\title{
Comparison of the Effects of Barefoot, Kinesio Tape, and Dynamic Tape on Static and Dynamic Balance in Subjects With Asymptomatic Flexible
}

\author{
One-bin Lim¹, PhD, PT, So-yeon Park², PhD, PT \\ ${ }^{1}$ Department of Physical Therapy, College of Health Science, Yonsei University, Wonju, ${ }^{2}$ Department of Physical Therapy, College of Health \\ Science, Sangji University, Wonju, Korea
}

\author{
Article Info \\ Received October 8, 2019 \\ Revised December 27, 2019 \\ Accepted January 22, 2020 \\ Corresponding Author \\ So-yeon Park \\ E-mail: soyeonparkpt@gmail.com \\ https://orcid.org/0000-0003-2328-0028
}

\section{Key Words}

Balance

Dynamic tape

Flexible flatfoot

Kinesio Tape
Background: Flat-footed persons with collapsed medial longitudinal arch lose flexibility after skeletal maturity, resulting in several deformities and soft tissue injuries. Although arch support taping is usually applied in the clinic to support the collapsed arch, research on the use of different types of tape for more efficient arch support in flat-footed persons is lacking.

Objects: The purpose of this study was to examine three conditions (barefoot, kinesio tape, and dynamic tape) and compare their effects on static and dynamic balance in persons with asymptomatic flexible flatfoot.

Methods: Twenty-two subjects (9 females and 13 males) with asymptomatic flexible flatfoot participated in this study. The subjects performed the Y-balance test to measure the composite reach score. The subjects also performed a 30-second standing test to measure the center of pressure (COP) path length and a walking test to measure anteroposterior and lateral variability using the Zebris FDM system. One-way repeated-measures analysis of variance compared the three conditions applied to the subjects' feet for each balance variable.

Results: The composite reach score significantly increased following the application of dynamic tape compared with barefoot and that of kinesio tape compared with barefoot. There was no significant difference in the COP path length during standing among the three conditions. Anteroposterior and lateral variability during walking significantly with dynamic tape application compared with barefoot.

Conclusion: The results of this study suggest that, in persons with asymptomatic flexible flatfoot, application of kinesio tape and dynamic tape may be effective in increasing the composite reach score in Y-balance test, whereas application of dynamic tape may be effective in reducing anteroposterior and lateral variability during walking.

\section{INTRODUCTION}

Flat-footed persons with collapsed medial longitudinal arch lose flexibility after skeletal maturity [1]. The subtalar and midtarsal joints show movement beyond the normal range of motion, and the foot continues to be pronated for a prolonged time during walking [2]. Flatfoot has been cited as a contributing factor to various lower limb overuse injuries [3], and it has been associated with plantar fasciitis [4], hallux rigidus [5], and medial tibial stress syndrome [6].

Arch support taping is usually applied in the clinic to individuals with flatfoot [3,7]. Arch support taping creates a force vector to shorten the foot and support the collapsed medial longitudinal arch [7]. Tapes being used for arch support taping in clinical practice are made of different materials. Kinesio tape is one of the most popular tapes for the management of musculoskeletal impairments, including flatfoot [8]. Kinesio tape is the closest to human skin and is believed to help correct flatfoot deformation via increased proprioceptive feedback from the feet [3]. Dynamic tape is another popular tape, and its material and properties are completely different from those of kinesio tape. It has very strong elastic resistance and recoil and has 200\% stretch and four-way stretch, allowing taping that can resist and decelerate, store energy, and assist motion without limiting the range of movement of activities of daily living or athletic performance [7]. Among the dynamic 
tape properties, strong elastic resistance and recoil properties may be more advantageous in arch support, but no comparative verification with kinesio tape has been done.

Balance, which refers to the ability to maintain the center of gravity within the body's base of support, is usually used to measure the function of the lower extremity [9]. To maintain upright standing balance, the central and peripheral components of the nervous system constantly interact to adjust body alignment and the center of gravity within the base of support [10]. The foot is the most distal segment of the lower extremity and represents a relatively small base of support for maintaining body balance; thus, it is reasonable that even small biomechanical changes in the support surface may affect the posture control strategy [11]. In particular, flatfoot may affect peripheral input via changes in joint mobility or surface contact area to maintain a stable base of support [11]. Previous study found that modified reverse-six taping in flexible flatfoot was improve the balance performance [11]. Many studies have been conducted to introduce various intervention methods and to verify their effectiveness in solving problems related to flatfoot [12-16]. To our knowledge, no previous study has determined the effect of arch support taping using tape made of various materials to static and dynamic balance ability to individuals with asymptomatic flexible flatfoot.

It is clinically important to know what type of tape is more effective and appropriate for arch support taping of individu- als with asymptomatic flexible flatfoot. Therefore, the aim of this study was to examine three conditions (barefoot, kinesio tape, and dynamic tape) and compare their effects on static and dynamic balance in persons with asymptomatic flexible flatfoot. We hypothesized that the composite reach scores, center of pressure (COP) path length, and anteroposterior and lateral variability would differ between three conditions.

\section{MATERIALS AND METHODS}

\section{Subjects}

A priori power analysis with G*Power ver. 3.1.9.4 (Franz Faul; University of Kiel, Kiel, Germany) was used to estimate the sample size. A pilot study with eight subjects with asymptomatic flexible flatfoot was used to achieve an effect size of 0.35 , an alpha level of $5 \%$, and power of $80 \%$ (calculated by partial $\eta 2$ of 0.11 ). The estimated sample size was 15 . Fiftyeight of the 80 volunteers did not meet the criteria and the remaining 22 met the criteria and were selected for this study (Figure 1). Twenty-two subjects (9 females and 13 males) with asymptomatic flexible flatfoot volunteered to participate in this study (Table 1). Subjects with a navicular height difference of $>10 \mathrm{~mm}$ in the navicular drop test, which indicates excessive pronation [11], and leg length difference $<5 \mathrm{~mm}$ [17] were included. Subjects with a history of lower leg surgery, who had any known allergies to taping, and with any other cause of lo-

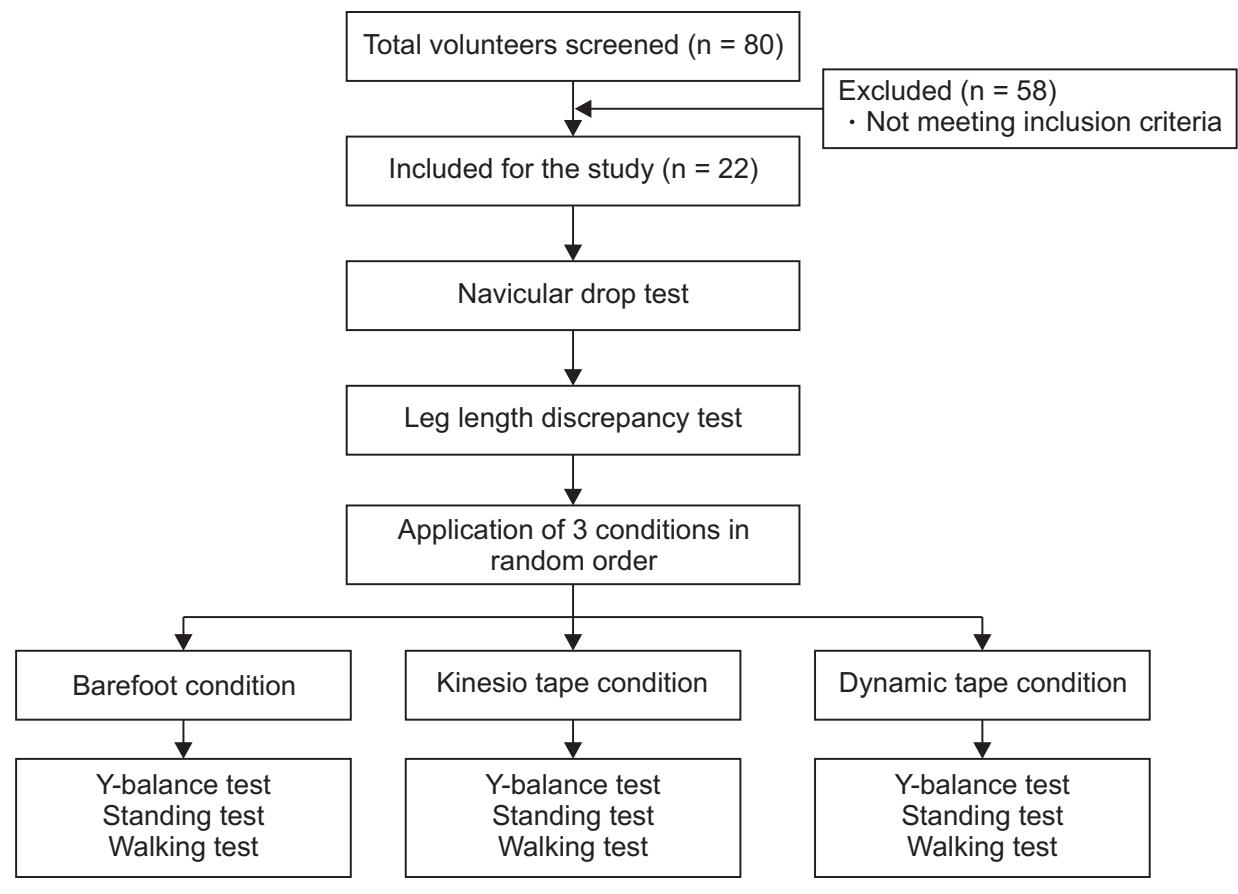

Figure 1. Study flowchart. 
calized or referred plantar foot pain were excluded [18].

Each subject signed an informed consent form, and the rights of each subject were protected.

\section{Instrumentation}

\section{1) Navicular drop test}

Flexible flatfoot was confirmed through the navicular drop test, for which the subjects flexed their knees $90^{\circ}$ in sitting position and placed their feet parallel to the floor. The examiner set their subtalar joint to neutral position and recorded the height of the navicular tubercle using a pen. The subjects then stood in a relaxed position without changing their foot position and kept their weight equal on both feet. A navicular height difference $>10 \mathrm{~mm}$ indicated flatfoot [11]. The intrarater reliability of the navicular drop test, which was determined using intraclass correlation coefficients $\left(\mathrm{ICC}_{3,1}\right)$, was $0.78(95 \%$ confidence interval, 0.34-0.93), indicating good intrarater reliability [19].

\section{2) Leg length discrepancy test}

Leg length difference was confirmed through the leg length discrepancy test, the subjects in the supine position using a tape and calculated as the distance between the anterior superior iliac spine and the medial malleolus [20]. During the test both legs were placed in a neutral position and close to each other to make measurement as standardized as possible.

\section{3) Y-balance test}

The Y-balance test, which assesses the dynamic balance of the lower extremity, comprised three parts [21] and used the FMS Y-balance test kit (Functional Movement Systems, Lynchburg, VA, USA). The subjects stood on the central footplate (Figure 2). The distal part of the right foot was at the starting

Table 1. Characteristics of the subjects ( $N=22)$

\begin{tabular}{lc}
\hline \multicolumn{1}{c}{ Parameter } & Value \\
\hline Age $(\mathrm{y})$ & $23.0 \pm 4.2$ \\
Height $(\mathrm{cm})$ & $169.5 \pm 7.0$ \\
Weight $(\mathrm{kg})$ & $69.5 \pm 14.2$ \\
Body mass index $\left(\mathrm{kg} / \mathrm{m}^{2}\right)$ & $24.0 \pm 3.6$ \\
Foot size $(\mathrm{mm})$ & $256.5 \pm 18.9$ \\
Right navicular drop $(\mathrm{mm})$ & $11.1 \pm 2.9$ \\
Left navicular drop $(\mathrm{mm})$ & $11.7 \pm 2.8$ \\
Right leg length $(\mathrm{mm})$ & $876.2 \pm 46.8$ \\
Left leg length $(\mathrm{mm})$ & $879.1 \pm 73.5$ \\
\hline
\end{tabular}

Values are presented as mean \pm standard deviation. line. While maintaining single-leg stance on the right leg and with their hands on their chest, the subjects reached with the left leg in the anterior, posteromedial, and posterolateral directions in relation to the stance foot by pushing the indicator box as far as possible. The subjects touched each direction once. Specifically, the testing order was completed as right anterior, right posteromedial, right posterolateral, left anterior, left posteromedial, and left posterolateral directions. Attempts were discarded if the subject failed to stand on one leg and push the indicator box, and he or she was asked to stand on one leg and push the indicator box again. The intrarater reliability of the Y-balance test, which was determined by $\mathrm{ICC}_{3,1}$, ranged from 0.84 to 0.87 (95\% confidence interval, 0.65-0.94) for the three reach directions, indicating good intrarater reliability [22].

\section{4) Pressure measurement plates}

The measurement of static balance throughout the 30-second standing and dynamic balance throughout the walking test was performed with a $2,122 \times 605 \times 21-\mathrm{mm}$ (length $\times$ width $\times$ height) Zebris pressure measurement plate FDM2 system (Zebris Medizintechnik GmbH, Isny, Germany) and original WinPDMS ver. 1.2.2 measuring software. Pressure data were collected at $100 \mathrm{~Hz}$. Two Zebris pressure measurement plate FDM-2 systems were used side by side. The 30-second standing test on the plate was used to measure the COP path length, which is a dependent variable [23]. The walking test, performed on the plate, measured anteroposterior and lateral variability, which are dependent variables [24].

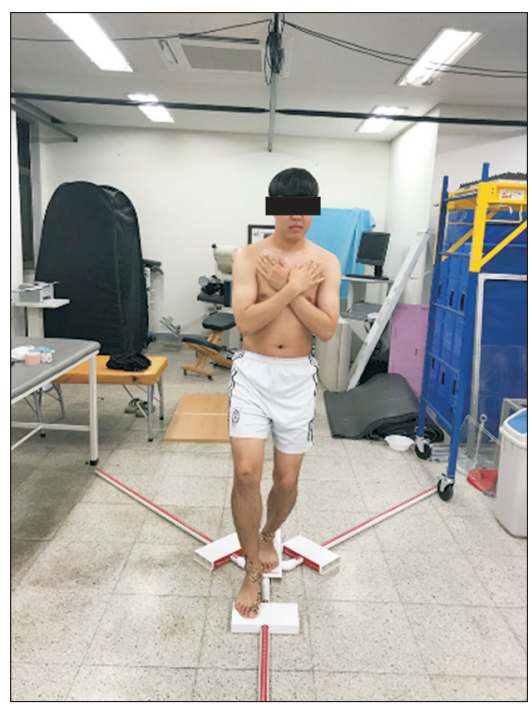

Figure 2. Y-balance test. 


\section{5) Taping methods and types}

The taping method for this study was the arch support taping technique, as described by Ryan Kendrick [7]. This technique starts at the great toe and is positioned in plantar flexion to create an artificial windlass mechanism in order to resist lengthening and flattening of the foot [7]. Two tape types were applied to the subjects: a 5-cm wide kinesio tape (Towatek Korea, Guri, Korea) and a 5-cm wide dynamic tape (Dynamic Tape, Port Vila, Vanuatu). The materials' properties of the two types differ [7]. Kinesio tape is made of cotton and Lycra and has a percentage of elongation ranging from $140 \%$ to $180 \%$. Kinesio tape has a rigid end point, and its resistance and recoil are weak. The direction of stretch is only longitudinal. The application position is generally in the lengthened position. The primary mode of action is neurophysiological effects, and the secondary mode of action is mechanical effects, i.e., resistive/restrictive. Meanwhile, dynamic tape is made of nylon/ Lycra or recycled polyethylene terephthalate/Lycra and has a percentage of elongation $>200 \%$. Dynamic tape had no rigid end point, and its resistance and recoil are strong (double layer measured at $10-15 \mathrm{~kg}$ ). The direction of stretch is longitudinal and transverse. The application position is in the shortened position. The primary mode of action is mechanical effects, i.e., deceleration and load absorption and assistance of movement, and the secondary mode of action is neurophysiological effects.

\section{Procedures}

The subjects first performed the navicular drop test; then, both leg lengths were measured. The subjects performed a total of three trials. The first trial was the Y-balance test, and the second trial was the 30-second standing test on the plate. The third trial was the walking test on the plate. The skin of each of the subjects was cleaned by removing the hair and removing any moisturizers. Taping was applied to all subjects continuously by one examiner to ensure consistency. The examiner is skilled at taping and is a certified dynamic taping instructor (level 1). The examiner removed the backing paper by tearing it, while avoided contact of fingers with the adhesive glue. The examiner applied the anchor (three or four finger widths) without tension. The examiner held the anchor and pressed in the opposite direction to the technique so that no tension is transmitted to the skin. Three experimental conditions (barefoot, kinesio tape, and dynamic tape) were performed in a random order to eliminate order effects (Figure 3). Taping was applied to both feet. The subjects did not wear shoes during the measurement. The subjects performed the Y-balance test using both legs. The dominant leg of the subjects was determined by asking the subjects which leg they use for kicking a ball [11], and it was used for data analysis. Static balance control during quiet standing was measured using the plate (Figure 4). The subjects were instructed to stand barefoot on the plate, with their feet together and their arms alongside their body [25]. When applicable, the subjects were asked to stare at a visual reference point located at eye level $2 \mathrm{~m}$ in front of them [25]. The standing test was performed for 30 seconds. The subjects were asked to sway as little as possible while standing. Dynamic balance control during walking was measured using the plate (Figure 5). Prior to the walking test, the subjects walked 1 minute for become familiarized with the plate. During the measurement, they walked on the plate with a self-selected walking velocity and stared straight ahead. After each trial, the subjects rested for 5 minutes to minimize fatigue.

\section{Data Analysis}

The data of the dominant leg of each subject were analyzed.
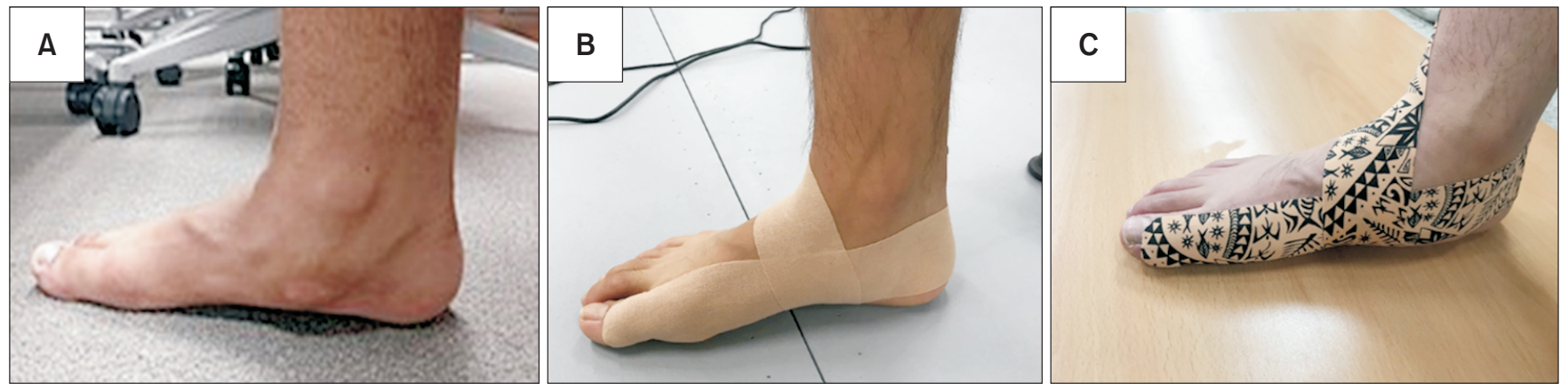

Figure 3. Three experimental conditions; (A) barefoot, (B) kinesio tape, (C) dynamic tape. 


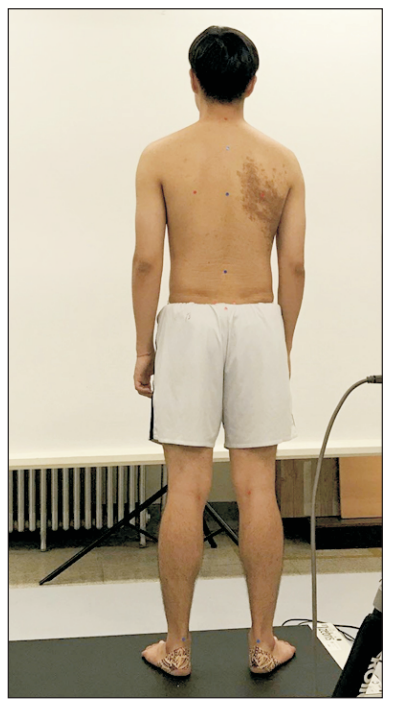

Figure 4. Standing test on the plate.

Among the subjects who participated in this study, the dominant leg of 21 was the right leg and that of one subject was the left leg. First, the data of the anterior, posteromedial, and posterolateral reach directions were analyzed through the Ybalance test. Means and standard deviations were calculated for the reach distance in each direction and leg length. Since reach distance is related to leg length, reach distance was normalized to leg length to allow the comparison among the three different experimental conditions. To express reach distance as a percentage of leg length, the normalized value was calculated as reach distance divided by leg length multiplied by 100 [22]. The composite reach distance was the sum of the three reach directions divided by three times the leg length and then multiplied by 100 [22]. Second, the Zebris processing program determined and restored the measured pressure data and calculated the COP and butterfly parameters automatically. The COP parameter is the COP path length (in $\mathrm{mm}$ ), which is the length of the total COP trajectory during standing. The butterfly parameters are anteroposterior and lateral variability during walking. Anteroposterior variability (in $\mathrm{mm}$ ) is the standard deviation of the intersection point in the anteroposterior direction, whereas lateral variability (in $\mathrm{mm}$ ) is the standard deviation of the lateral symmetry [26].

\section{Statistical Analysis}

One-sample Kolmogorov-Smirnov test was performed to determine whether continuous data approximated a normal distribution. One-way repeated-measures analysis of variance was used to compare the composite reach score, COP path

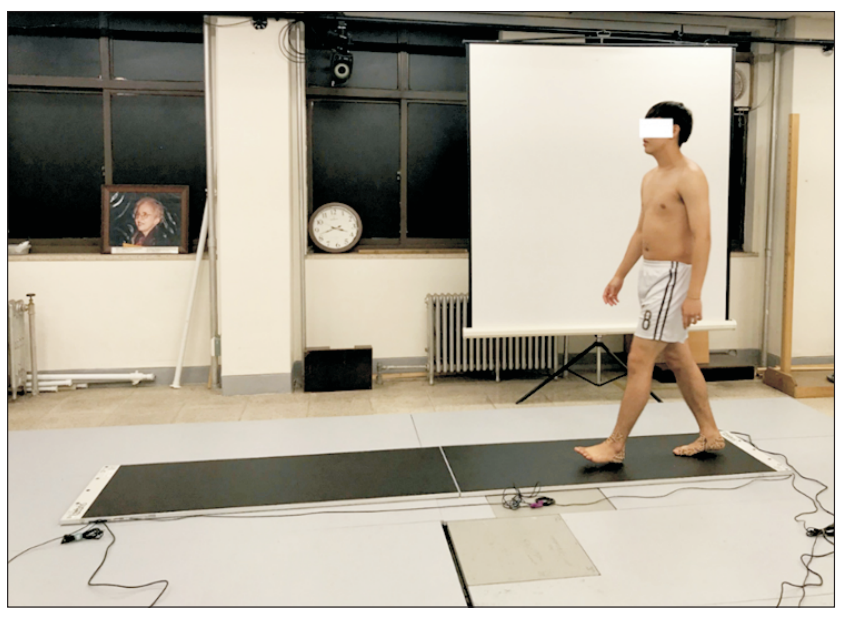

Figure 5. Walking test on the plate.

length, and anteroposterior and lateral variability of the three conditions (barefoot, kinesio tape, and dynamic tape). The level of significance was set at $\alpha=0.05$. Bonferroni adjustment was used to eliminate any differences and statistical significance was set at $0.017(0.05 / 3)$. Analyses were performed using IBM SPSS ver. 25.0 (IBM Corp., Armonk, NY, USA).

\section{RESULTS}

The composite reach score, COP path length, and anteroposterior and lateral variability of the three conditions are shown in Figure 6.

The composite reach scores were $79.12 \% \pm 17.24 \%$ for barefoot, $91.20 \% \pm 14.03 \%$ for kinesio tape, and $91.82 \% \pm 13.56 \%$ for dynamic tape. There were significant differences between three conditions in the composite reach scores $(\mathrm{F}=10.383, \mathrm{p}=$ 0.002). The composite reach score significantly increased following the application of dynamic tape compared with barefoot $(p=0.001)$. The composite reach score significantly increased following the application of kinesio tape compared with barefoot $(p=0.007)$. There were no significant differences between barefoot and dynamic tape in the composite reach scores ( $p=$ $0.670)$.

The COP path length was $308.72 \pm 198.36 \mathrm{~mm}$ for barefoot, $247.77 \pm 137.26 \mathrm{~mm}$ for kinesio tape, and $233.09 \pm 69.70 \mathrm{~mm}$ for dynamic tape. There was no significant difference among the three conditions in COP path length during standing ( $\mathrm{F}=$ 2.634, $\mathrm{p}=0.098$ ).

Anteroposterior variability was $2.86 \pm 2.06 \mathrm{~mm}$ for barefoot, $2.19 \pm 1.29 \mathrm{~mm}$ for kinesio tape, and $1.52 \pm 0.49 \mathrm{~mm}$ for 

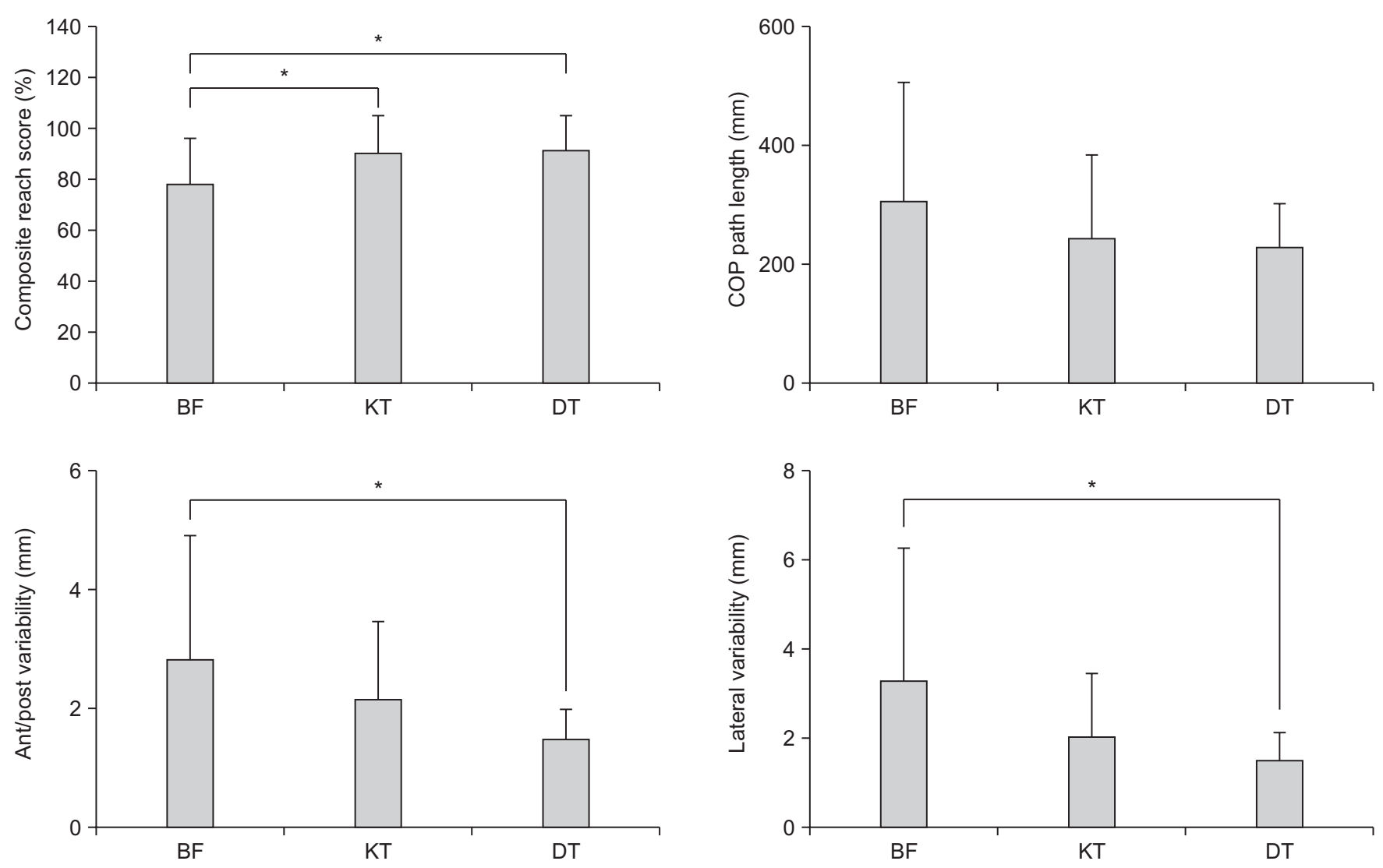

Figure 6. Comparison of the composite reach score, COP path length, and anteroposterior and lateral variability of the three conditions. Error bar: standard deviation. COP, center of pressure; Ant/post, anteroposterior; BF, barefoot; KT, kinesio tape; DT, dynamic tape. *p<0.017.

dynamic tape. Lateral variability was $3.35 \pm 2.93 \mathrm{~mm}$ for barefoot, $2.10 \pm 1.37 \mathrm{~mm}$ for kinesio tape, and $1.55 \pm 0.61 \mathrm{~mm}$ for dynamic tape. There were significant differences among the three conditions in anteroposterior $(\mathrm{F}=4.892, \mathrm{p}=0.019)$ and lateral variability $(\mathrm{F}=5.419, \mathrm{p}=0.019)$. Anteroposterior and lateral variability during walking significantly decreased following the application of dynamic tape compared with barefoot (anteroposterior variability: $\mathrm{p}=0.009$; lateral variability: $p=0.009)$. There were no significant differences between barefoot versus kinesio tape and kinesio tape versus dynamic tape in terms of anteroposterior (barefoot versus kinesio tape: $p=0.163$; kinesio tape versus dynamic tape: $p=0.037$ ) and lateral variability (barefoot versus kinesio tape: $\mathrm{p}=0.076$; $\mathrm{ki}-$ nesio tape versus dynamic tape $\mathrm{p}=0.091$ ).

\section{DISCUSSION}

This study investigated whether the composite reach score, COP path length, and anteroposterior and lateral variability could be changed by three conditions (barefoot, kinesio tape, and dynamic tape) in subjects with asymptomatic flexible flatfoot. The composite reach score increased significantly with dynamic tape compared with barefoot. A previous study revealed that the reach distance on the Y-balance test significantly decreased in subjects with asymptomatic flexible flatfoot than in those with normal feet [27]. In our study, we applied dynamic tape as an intervention to improve dynamic balance in subjects with asymptomatic flat feet, and our results showed that dynamic tape improved dynamic balance compared with barefoot. These results are in close agreement with those of previous studies [28]. A previous research showed that dynamic tape increased reach distance in the star excursion balance test compared to rigid athletic tape and barefoot [28]. Our results can be explained by the dynamic tape's strong elastic resistance and recoil. Dynamic tape has to act like a bungee cord, which strongly decelerates a falling body and bounce it back [7]. The use of dynamic tape can reduce navicular drop and resist the flattening of the medial longitudinal arch [7]. Dynamic taping, which holds the foot firmer and does not limit the range of motion during the Y-balance test, is presumed to improve dynamic balance than barefoot. Therefore, we recommend applying dynamic tape to improve dynamic balance during the 
Y-balance test.

In this study, the composite reach score significantly increased following the application of kinesio tape compared with barefoot. The reason for these findings can be explained by the neurophysiological effects of kinesio tape. The kinesio tape may increase afferent input and improve proprioception [29]. It is inferred that dynamic balance is improved by increasing the stability of the foot through an increase in proprioception. A previous study, which had a similar experimental design, aimed to determine if applying kinesio tape to an unstable ankle can improve performance in the star excursion balance test [29]. The results of the study showed that kinesio tape has superior effect than athletic tape in patients with first-degree ankle sprain [29]. Our findings were consistent with previous findings regarding dynamic balance when using kinesio tape. Therefore, we recommend applying kinesio tape to improve dynamic balance during the Y-balance test.

Our data indicated that there was no significant difference in the COP path length during standing among the three conditions. The ability to maintain the body's center of mass without possible movement is called static balance [30]. In this study, the COP path length was observed to compare the static balance among three conditions, and results showed that static balance was not significantly different in no-tape, kinesio-tape and dynamic-tape conditions. This result was similar to that of Choi and Seo [31], which showed no significant difference in static balance among the short-foot exercise group, the lowdye taping group, and the control group. A previous study reported that visual information provides sufficient feedback for the compensatory motion of balance impairment [32]. Thus, our findings inferred that there was no significant difference in the COP path length among the three conditions because the subjects were provided with sufficient visual information while standing.

Our study found that anteroposterior and lateral variability during walking significantly decreased with dynamic tape compared with barefoot. In our study, anteroposterior and lateral variability were used to determine dynamic balance during walking. A previous study showed that people with multiple sclerosis have greater anteroposterior and lateral variability than healthy people during walking [24]. Based on previous findings, the results of our study showed that anteroposterior and lateral variability are reduced when dynamic tape was applied. It may be inferred that the application of dynamic tape helped improve balance while walking. The reason for this result may be due to the mechanical effects of dynamic tape. Dynamic tape provided mechanical effect, which influences the biomechanical properties of biological tissues, maximizes load absorption, and assists motion without limiting range of movement $[7,33]$. When the foot is placed on the ground, the resistance of the dynamic tape may be overcome for the navicular arch to drop [34]. Dynamic tape helps in slowing down the navicular through rotation control and in creating an artificial windlass mechanism to further resist lengthening and flattening of the foot $[7,35]$. Therefore, arch support taping using dynamic tape helps shift midfoot pressures laterally to reduce over-pronation as well as anteroposterior and lateral variability during walking. This is an important finding for clinicians, as it indicates that dynamic tape is an effective intervention for dynamic balance suggesting that dynamic tape application may be effective for dynamic balance when applied to subjects with asymptomatic flexible flatfoot.

Some limitations of this study need be considered for future studies. First, visual feedback was not considered during the standing test. Future research should examine the effects of not providing visual feedback for static balance and providing visual feedback during the standing test. Second, all subjects in this study were young adults with asymptomatic flexible flatfoot. There is a limit to the generalization of the results of this study. Further studies are needed to examine the effects of dynamic taping on static and dynamic balance in flexible flat-footed subjects with different age groups or who have pain. Finally, this study included only standing and walking activities. Further studies on flatfoot should include other functional activities such as jumping and running.

\section{CONCLUSIONS}

This study was conducted to examine the effects of barefoot, kinesio tape, and dynamic tape on the composite reach score, COP path length, and anteroposterior and lateral variability in subjects with asymptomatic flexible flatfoot. Our results showed that the composite reach score was significantly with dynamic tape and kinesio tape application compared with barefoot. There was no significant difference in the COP path length during standing among the three conditions. Anteroposterior and lateral variability during walking significantly decreased with dynamic tape application compared with bare- 
foot. Based on the results of this study, we suggest that, in persons with asymptomatic flexible flatfoot, application of kinesio tape and dynamic tape may be effective in increasing the composite reach score in Y-balance test, whereas application of dynamic tape may be effective in reducing anteroposterior and lateral variability during walking.

\section{CONFLICTS OF INTEREST}

No potential conflict of interest relevant to this article was reported.

\section{AUTHOR CONTRIBUTIONS}

Conceptualization: So-yeon Park. Data curation: One-bin Lim, So-yeon Park. Formal analysis: One-bin Lim, So-yeon Park. Funding acquisition: One-bin Lim. Investigation: Onebin Lim, So-yeon Park. Methodology: One-bin Lim, So-yeon Park. Project administration: One-bin Lim, So-yeon Park. Resources: One-bin Lim, So-yeon Park. Software: One-bin Lim. Supervision: So-yeon Park. Validation: One-bin Lim. Visualization: One-bin Lim. Writing - original draft: One-bin Lim. Writing - review \& editing: So-yeon Park.

\section{ORCID}

One-bin Lim, https://orcid.org/0000-0002-5281-3463

\section{REFERENCES}

1. Romeo G, Bianchi A, Cerbone V, Parrini MM, Malerba F, Martinelli N. Medial cuneiform opening wedge osteotomy for correction of flexible flatfoot deformity: trabecular titanium vs. bone allograft wedges. Biomed Res Int 2019;2019:1472471.

2. Lange B, Chipchase L, Evans A. The effect of low-Dye taping on plantar pressures, during gait, in subjects with navicular drop exceeding $10 \mathrm{~mm}$. J Orthop Sports Phys Ther 2004;34(4):201-9.

3. Luque-Suarez A, Gijon-Nogueron G, Baron-Lopez FJ, LabajosManzanares MT, Hush J, Hancock MJ. Effects of kinesiotaping on foot posture in participants with pronated foot: a quasi-randomised, double-blind study. Physiotherapy 2014; 100(1):36-40.

4. Graham ME, Jawrani NT, Goel VK. Evaluating plantar fascia strain in hyperpronating cadaveric feet following an extraosseous talotarsal stabilization procedure. J Foot Ankle Surg 2011;50(6):682-6.

5. Beeson P, Phillips C, Corr S, Ribbans WJ. Hallux rigidus: a cross-sectional study to evaluate clinical parameters. Foot (Edinb) 2009;19(2):80-92.

6. Raissi GR, Cherati AD, Mansoori KD, Razi MD. The relationship between lower extremity alignment and Medial tibial stress syndrome among non-professional athletes. Sports Med Arthrosc Rehabil Ther Technol 2009;1(1):11.

7. McNeill W, Pedersen C. Dynamic tape. Is it all about controlling load? J Bodyw Mov Ther 2016;20(1):179-88.

8. González-Iglesias J, Fernández-de-Las-Peñas C, Cleland JA, Huijbregts P, Del Rosario Gutiérrez-Vega M. Short-term effects of cervical kinesio taping on pain and cervical range of motion in patients with acute whiplash injury: a randomized clinical trial. J Orthop Sports Phys Ther 2009;39(7):515-21.

9. Guskiewicz KM, Perrin DH. Research and clinical applications of assessing balance. J Sport Rehabil 1996;5(1):45-63.

10. Alexander KM, LaPier TL. Differences in static balance and weight distribution between normal subjects and subjects with chronic unilateral low back pain. J Orthop Sports Phys Ther 1998;28(6):378-83.

11. Cote KP, Brunet ME, Gansneder BM, Shultz SJ. Effects of pronated and supinated foot postures on static and dynamic postural stability. J Athl Train 2005;40(1):41-6.

12. Yang SH, Shin YI, Lee JY. The effect of modified reversesix taping on the balance and gait performance in Pes planus - pilot study. J Korean Acad Orthop Man Phys Ther 2016;22(1):35-41.

13. Lee SM, Lee DY, Hong JH, Yu JH, Kim JS. The effect of elastic and non-elastic tape on flat foot. Indian J Sci Technol 2015; 8(26):1-5.

14. Kodithuwakku Arachchige SNK, Chander H, Knight A. Flatfeet: biomechanical implications, assessment and management. Foot (Edinb) 2019;38:81-5.

15. Wu FL, Shih YF, Lee SH, Luo HJ, Wang WT. Can short-term effectiveness of anti-pronation taping predict the long-term outcomes of customized foot orthoses: developing predictors to identify characteristics of patients with plantar heel pain likely to benefit from customized foot orthoses. BMC Musculoskelet Disord 2019;20(1):264 .

16. Yoo KT. Effects of modified low-dye taping and foot intrinsic muscle strengthening exercise on plantar pressure in flexible 
flat foot. J Int Acad Phys Ther Res 2017;8(3):1235-41.

17. Hong JA. Effects of orthotic insole on peak plantar pressure, center of pressure trajectory, and muscle activity of lower limb during one leg standing in adults with flexible flat foot. Seoul, Yonsei University, Master's Thesis. 2012.

18. Abd El Salam MS, Abd Elhafz YN. Low-dye taping versus medial arch support in managing pain and pain-related disability in patients with plantar fasciitis. Foot Ankle Spec 201 1;4(2):86-91.

19. Vauhnik R, Turk Z, Pilih IA, Mičetić-Turk D. Intra-rater reliability of using the navicular drop test for measuring foot pronation. Hrvat Športskomed Vjesn 2006;21(1):8-11.

20. Sayed-Noor AS, Hugo A, Sjödén GO, Wretenberg P. Leg length discrepancy in total hip arthroplasty: comparison of two methods of measurement. Int Orthop 2009;33(5):1 189-93.

21. Shaffer SW, Teyhen DS, Lorenson CL, Warren RL, Koreerat CM, Straseske CA, et al. Y-balance test: a reliability study involving multiple raters. Mil Med 2013;178(11):1264-70.

22. Plisky PJ, Rauh MJ, Kaminski TW, Underwood FB. Star excursion balance test as a predictor of lower extremity injury in high school basketball players. J Orthop Sports Phys Ther 2006;36(12):911-9.

23. Nagymáté G, Kiss RM. Balancing strategy differences in bilateral knee osteoarthritis patients. Paper presented at: 2017 13th IASTED International Conference on Biomedical Engineering (BioMed); 2017 Feb 20-21; Innsbruck, Austria. Innsbruck: IEEE; 2017;154-7.

24. Kalron A, Frid L. The "butterfly diagram": a gait marker for neurological and cerebellar impairment in people with multiple sclerosis. J Neurol Sci 2015;358(1-2):92-100.

25. Maktouf W, Durand S, Boyas S, Pouliquen C, Beaune B. Combined effects of aging and obesity on postural control, muscle activity and maximal voluntary force of muscles mobilizing ankle joint. J Biomech 2018;79:198-206.

26. Fan Y, Li Z, Han S, Lv C, Zhang B. The influence of gait speed on the stability of walking among the elderly. Gait Posture 2016;47:31-6.
27. Dabholkar A, Shah A, Yardi S. Comparison of dynamic balance between flat feet and normal individuals using star excursion balance test. Indian J Physiother Occup Ther 2012;6(3):33-7.

28. Dogan FE. The effect of different taping techniques to lower extremity jumping performance and dynamic postural control. Ankara, Gazi University, Master's Thesis. 2015.

29. Mohamed MA, Radwan NL, Azab ASR. Effect of kinesio-taping on ankle joint stability. Int J Med Res Health Sci 2016;5(5):518.

30. Chen CL, Yeung KT, Wang CH, Chu HT, Yeh CY. Anterior anklefoot orthosis effects on postural stability in hemiplegic patients. Arch Phys Med Rehabil 1999;80(12):1587-92.

31. Choi YJ, Seo HK. The effect of short foot exercise and lowdye taping on foot alignment, plantar foot pressure and static balance in adults with flat foot. J Korean Soc Rhythm Exerc 2018;11(2):71-80.

32. McKeon PO, Ingersoll CD, Kerrigan DC, Saliba E, Bennett BC, Hertel J. Balance training improves function and postural control in those with chronic ankle instability. Med Sci Sports Exerc 2008;40(10):1810-9.

33. Kendrick RJ, Kendrick YI. 'Active' Dynamic Taping for medial longitudinal arch support, applied in the shortened position increases navicular height, reduces foot length and decreases the magnitude of navicular drop between non weight bearing and weight bearing more than 'non-active' taping: a preliminary investigation. Dynamic tape [Internet]. 2014 Feb 1 [cited 2019 Dec 1]. Available from: https://www.dynamictapefrance.fr/wp-content/uploads/2015/05/Dynamic-Taping-forarch-support2014.pdf.

34. Falcão D. Use of dynamic tape in spastics walking children with cerebral palsy - a case series study. EACD Education [Internet]. 2019 Mar 8 [cited 2019 Dec 1]. Available from: http://edu.eacd.org/node/599.

35. Bage D. The effects of Dynamic Tape for medial longitudinal arch support on navicular height and plantar pressures during running activity. Chichester, University of Chichester, Master's Thesis. 2017. 